Review

\title{
Energy-Efficient Through-Life Smart Design, Manufacturing and Operation of Ships in an Industry 4.0 Environment
}

\author{
Joo Hock Ang ${ }^{1,2, *}$, Cindy Goh ${ }^{2}$, Alfredo Alan Flores Saldivar ${ }^{2}$ and Yun $\mathrm{Li}^{2, *}$ \\ 1 Sembcorp Marine Ltd., Singapore 628054, Singapore \\ 2 School of Engineering, University of Glasgow, Glasgow G12 8LT, UK; cindy.goh@glasgow.ac.uk (C.G.); \\ a.flores-saldivar@research.gla.ac.uk (A.A.F.S.) \\ * Correspondence: joohock.ang@sembmarine.com (J.H.A.); yun.li@glasgow.ac.uk (Y.L.); \\ Tel.: +065-62627989 (J.H.A.); +141-330-4930 (Y.L.)
}

Academic Editor: Carl-Fredrik Lindberg

Received: 30 December 2016; Accepted: 24 April 2017; Published: 29 April 2017

\begin{abstract}
Energy efficiency is an important factor in the marine industry to help reduce manufacturing and operational costs as well as the impact on the environment. In the face of global competition and cost-effectiveness, ship builders and operators today require a major overhaul in the entire ship design, manufacturing and operation process to achieve these goals. This paper highlights smart design, manufacturing and operation as the way forward in an industry 4.0 (i4) era from designing for better energy efficiency to more intelligent ships and smart operation through-life. The paper (i) draws parallels between ship design, manufacturing and operation processes, (ii) identifies key challenges facing such a temporal (lifecycle) as opposed to spatial (mass) products, (iii) proposes a closed-loop ship lifecycle framework and (iv) outlines potential future directions in smart design, manufacturing and operation of ships in an industry 4.0 value chain so as to achieve more energy-efficient vessels. Through computational intelligence and cyber-physical integration, we envision that industry 4.0 can revolutionise ship design, manufacturing and operations in a smart product through-life process in the near future.
\end{abstract}

Keywords: energy efficiency; industry 4.0 (i4); smart design; smart manufacturing; through-life design; cyber-physical systems

\section{Introduction}

Ships today carry $90 \%$ of international trade [1] and are regarded as one of the most energy-efficient modes of transport in terms of distances of freight transported for same energy input, as compared to land and air transport [2]. According to International Energy Outlook 2016 [3], total world energy consumption is expected to rise $48 \%$, from 549 quadrillion British thermal units (Btu) in 2012 to 815 quadrillion Btu in 2040. Marine transportation consumed 12.48 quadrillion Btu of energy, which amounts to $12 \%$ of total transportation consumption and around $2.2 \%$ of world energy consumption in 2012 (see Figure 1). 


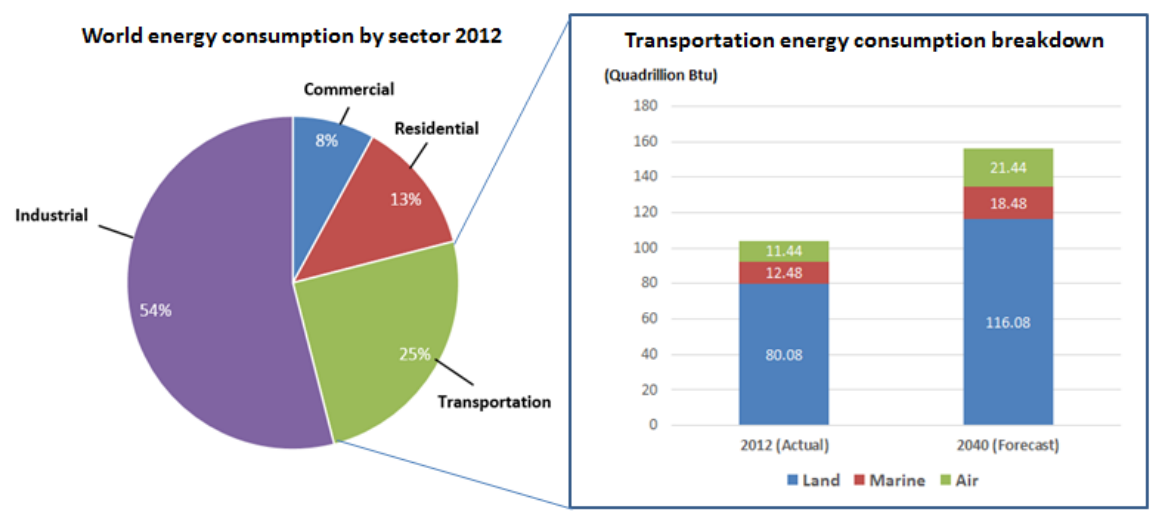

Figure 1. World energy consumption (2012) and breakdown by transportation sector; data obtained from [3].

From the graph above, one can observe that the energy consumption for marine vessels is expected to increase $32 \%$ to 18.48 Btu by 2040 . One of the main reasons for this slow growth (as compared to land and air transport) can be attributed to more stringent environmental regulations that are being introduced in the marine industry to reduce energy consumption and carbon emissions. As part of the energy efficiency design index (EEDI) regulation implemented by the International Maritime Organisation (IMO) in 2013, ships built after 2025 will be at least 30\% more fuel efficient [4]. As a consequence, eco-friendly shipping and energy efficiency are now key design criteria for the construction of new ships [5]. An energy-efficient ship is one that is designed to consume the minimum fuel or power during operation and constructed using minimal resources and energy. Fuel price volatility is another top concern for ship operators. Fuel is the single highest expenditure for ship operations which accounts for 50 to 60 percent of the overall costs and reducing fuel consumption by just 1 percent can mean an annual saving of $\$ 300,000$ per year for a large container vessel [6]. Consuming less fuel and energy helps to improve the shipyard's and ship operator's competitiveness by maximising construction and operational cost savings as well as reducing harm to the environment.

To reduce the dependency on designers' experience and manual labour, shipyards already started using simulations and information technology (IT) in the ship design and manufacturing process many years ago. With more powerful computers and the introduction of i4, advance simulations and i4 associated technologies will play an even more important role in producing more energy-efficient, cost-effective and innovative ships. From the ship design perspective, examples of reducing fuel consumption include the development of more efficient hull forms so as to reduce the overall resistance during operations and the use of energy-saving devices such as contra-rotating propellers and Kort nozzles [7]. During the ship manufacturing process, energy can be conserved through active monitoring of a shipyard's energy consumption and smart energy management system. Once the vessel is constructed and delivered to the owners, ship operators endeavour to operate their vessel in the most energy-efficient manner. This will help reduce fuel consumption and minimise pollution to the environment. An emerging trend in manufacturing-industry 4.0, which integrates cyber and physical systems for smart design and manufacturing - has the potential to transform how ships will be designed, built and even operated in the future.

The next section of this paper provides an overview of key processes in the ship's lifecycle and i4. It identifies areas where more attention could be devoted to creating further improvements in overall energy efficiency through the entire product life-cycle. Section 3 discusses possible directions of how i4 can be applied to improve energy efficiency for each lifecycle of ships and highlight some of its key challenges. Following this, a closed-loop framework that integrates the various i4 technologies throughout the entire ship lifecycle is proposed and discussed in Section 4. In same section, key milestones and potential impacts of i4 on smart ship design, manufacturing and operation are discussed. Section 5 concludes the paper. 


\section{Ship Lifecycle and Industry 4.0}

The world is getting more connected and the needs of customers are becoming more demanding and dynamic. Shipyards today need to design and produce more innovative and energy-efficient vessels in order to stay competitive. Unlike consumer products where the components are mostly homogenous (low mix) and manufactured in large quantity (high volume), ships are considered engineering structures that are highly customised (high mix) and constructed in low quantities (low volume). From an i4 perspective, consumer products are regarded as a "spatial character" of smart design and manufacturing. On an opposing horizon, ships can be built as a "smart product through-life", which is regarded as a "temporal character" of smart design and manufacturing. "Spatial character" here relates to quantity, while "temporal character" is associated with time (lifecycle). A comparison between consumer products and engineering structures is provided in Table 1 below.

Table 1. Comparison between consumer products and engineered structures.

\begin{tabular}{ccc}
\hline Parameters & Consumer Products & Engineering Structures \\
\hline Product types & $\begin{array}{c}\text { Mobile phones, personal computer, } \\
\text { television, refrigerator }\end{array}$ & Trains, planes, ships \\
\hline Manufacturing characteristic & Mass produced-low mix, high volume & Highly customised-high mix, low volume \\
\hline i4 characteristic & Spatial & Temporal \\
\hline Cost per unit & Low (below $\$ 10,000)$ & High (more than $\$ 1$ million) \\
\hline Product lifespan & $3-10$ years $[8]$ & 20-30 years \\
\hline
\end{tabular}

From Table 1, we can see distinct differences in the way both consumer products and engineering structures are manufactured and utilised. In particular, most consumer products are designed with a lifespan of less than 10 years, while engineered structures are designed to last up to 30 years, which makes it more important to consider the product lifecycle. Hence, it is necessary that the two product types should be treated separately in order to develop more targeted and effective solutions. It is observed that the current focus of i4 is on the manufacturing of consumer products and it has not so far been applied to manufacturing of engineering structures such as ships, trains, or infrastructure. It is therefore important to consider the characteristics of such 'highly customised' products in order to improve the overall energy efficiency.

\subsection{Ship Design, Manufacturing and Operation}

Ships are built to customised specifications, whereby the design and production are highly individualised. New environmental regulations also have an impact on how ships are designed, manufactured and operated. These regulations include controls on exhaust emissions, installation of fuel-saving devices and the push for more efficient hull form designs [5]. Therefore, systems and processes need to be more flexible and adaptive to customisation and production changes. In considering the 'spatial aspect' in ship design and manufacturing, it is important to look at the various stages of the design and manufacturing process during the entire lifecycle in order to improve the overall energy efficiency. The product lifecycle and key milestones in a typical ship's lifetime are provided in Figure 2.

From the above figure, it becomes clear that there are many stages and sub-activities that influence the buildability and operability of a ship, which in turn affects the overall energy efficiency. Ship design, manufacturing and operation possess the highest impact and influence in terms of energy consumption and therefore will be the focus in this paper. 


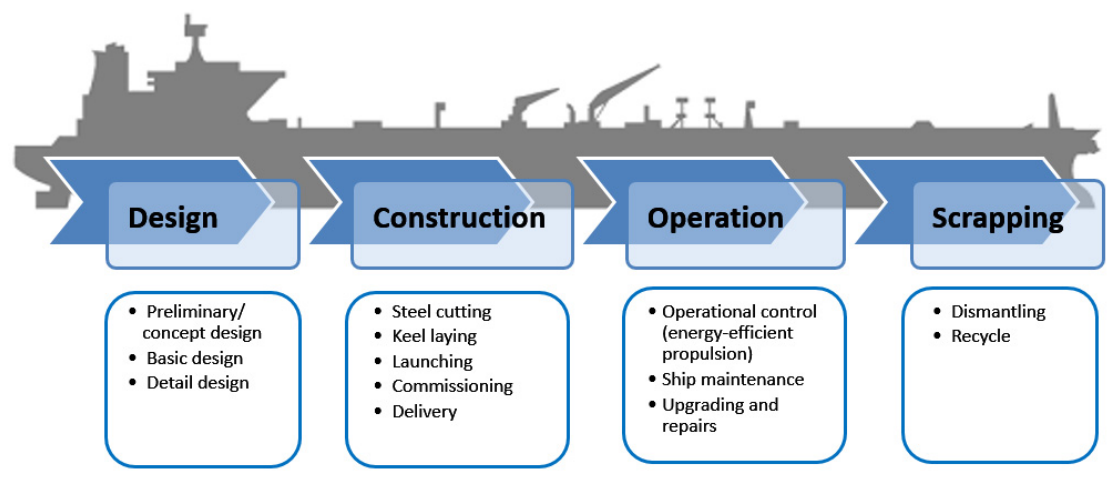

Figure 2. Ship lifecycle and key milestones.

\subsection{Industry 4.0 and Its Value Chain}

Industry 4.0 first originated from a high-tech strategy project from the German government in 2011 [9]. Often referred to as the fourth industrial revolution, it aims to merge the real and virtual space through cyber-physical systems to achieve maximum autonomy and efficiency. i4 allows a paradigm shift from "centralised" to "decentralised" production, a reversal of the logic of production process thus far. There are many studies that describe the basic components and enabling technologies of i4; [10] is one of the earliest documents that listed the key actions needed for successful i4 implementation. It identified the internet of things (IoT) and services as key enablers for smart factories; [11] identified the four key components of i4 as cyber-physical system, IoT, Internet of service and smart factories; [12] added visual computing as part of i4 key technologies among others, including semantic technologies, IoT, product lifecycle management, industrial big data, cybersecurity, intelligent robotics and industrial automation; and reference [13] listed the enabling technologies for smart factories as IoT, cloud-based application, data analytics, smart robotics, integrated product-production simulation and additive manufacturing. Considering the numerous interpretations, we summarised i4 as a collaborative network that combines seven key enabling technologies, namely intelligent robots, automated simulations, IoT, cloud computing, additive manufacturing, augmented reality and big data analytics. Figure 3 provides an overview of i4, depicting the development timeline of the four Industrial Revolutions with their key features as well as core technologies for i4.

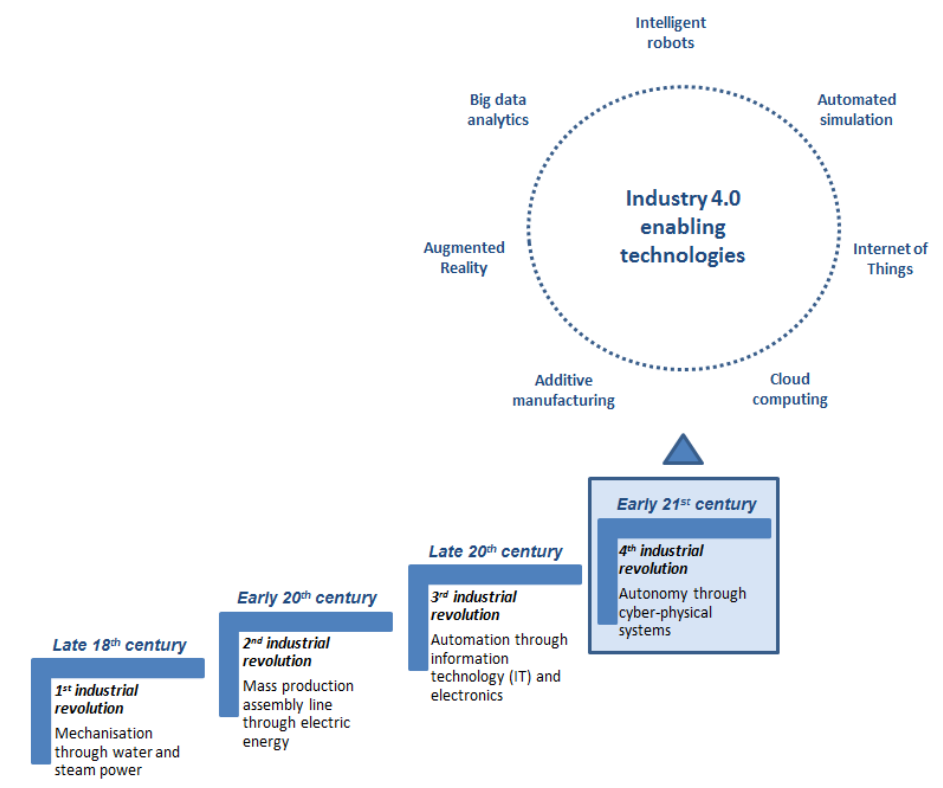

Figure 3. Industry 4.0 development timeline and enabling technologies. 
Since its inception, i4 has gained tremendous interest worldwide, with many major manufacturing nations investing heavily to capitalise on this new trend and stimulate more manufacturing output. In Europe, German government invested $€ 200$ million to spur i4 research across government, academia and business [14] as part of their "high-tech strategy 2020" initiative. United Kingdom government also committed to fund $£ 6$ million to co-develop advance manufacturing technology standards [15]. Separately, Basque government had also launched "Basque 4.0" to develop industry of the future [16]. In United State (USA), "Smart Manufacturing Leadership Coalition" was initiated, where public-private investment of USD 140 million were made to develop new technology solutions in advanced manufacturing [17]. In Asia, China initiated "Made in China 2025", which is a 10-year government program focusing on automation and cyber physical systems [18]. South Korea initiated "Manufacturing Innovation 3.0" [19], where the government invested USD 16.75 billion in robotic technology and aim to build 10,000 smart factories by 2020 for its smart manufacturing ecosystem [18]. Smart factories represent USD 139 billion value stake for Japan, which recently launched "Industrial Value Chain Initiative" to connect its factories worldwide [18]. Taiwan initiated "Productivity 4.0", where the government aim to invest USD 1.12 billion to elevate its status in global supply chain [19]. Singapore government also dedicated SGD 3.2 billion under its "Research, Innovation and Enterprise (RIE) 2020" plan to support research in advance manufacturing and engineering [20]. An overview of worldwide initiatives toward i4 is illustrated in Figure 4.

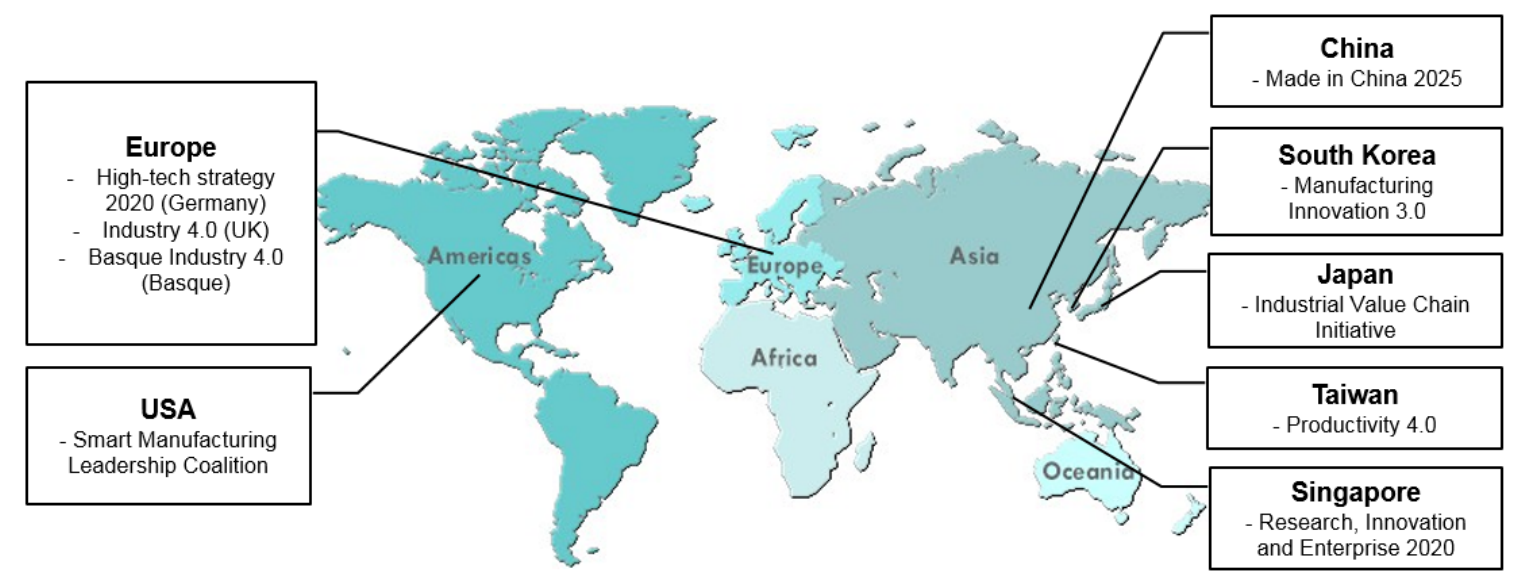

Figure 4. Worldwide initiatives toward i4.

One of the main goals of i4 is to achieve mass customisation at minimum production cost that is close to mass production. This is achieved through innovation, lower costs, better responses to customer needs, optimal solutions, intelligent systems, and alternatives towards on-demand production. This is enabled by recent advances in industrial digitalisation and the Internet where manufacturing value chain in the physical world can be seamlessly integrated with its virtual copy in cyberspace (digital-twin), thereby transforming the way decision-making and business are done in the traditional manufacturing environment [21]. The enabling technologies of i4 can be summarised as follows.

- Intelligent robots-Next-generation robots are evolving towards greater functionality when coupled with other i4 technologies as they become more autonomous, flexible and cooperative by interacting with one another and in closer collaboration with humans [22].

- Automated simulations-Simulations are used to mirror the physical world in a virtual model, as is already used in most design processes. Through i4, future simulation will move towards smarter design to automate the "test-and-optimise" process and will be used more extensively in shipyard and ship operations. 
- Internet of things (IoT)—IoT is used to link any objects (things) in the physical world having a virtual representation on the Internet [12]. It allows field devices to communicate and interact with one another within an i4 environment and helps to decentralise analytics and decision-making, thereby enabling real-time responses.

- Cloud computing-Cloud computing is a set of IT services that are provided over a network and with the ability to scale up or down depending on users' requirements [23]. It allows machine data and functionalities to be deployed on the cloud, thereby enabling more data-driven technologies and monitoring systems within the i4 environment.

- Additive manufacturing (AM) - AM refers to a cluster of processes that produce objects by adding material rather than removing from a solid block [24]. With i4, AM methods can be widely used to produce batches of customised products that offer construction advantages such as complex and lightweight design.

- Augmented reality (AR) - AR turns the real environment into a digital interface by placing virtual objects in the real world. Though i4, companies can make use of AR to provide employees with real-time information to improve decision-making and work procedures through AR devices. AR can also help create digitalised visual workflow to aid in the training of workers, as illustrated in [12].

- Big data analytics-Big data analytics is used to describe very large or complex datasets and can be used within i4 to support real-time decision-making via the collection and evaluation of data from various sources within and outside of the organisation.

It is important to note that, while each of the above i4 technologies is useful in itself, the key concept of i4 is to combine these technologies and allow them to collaborate with each other in order to achieve seamless integration of all activities. As mentioned at the beginning of this section, while i4 is rapidly gaining headway in general manufacturing such as consumer products, it is still not widely considered for engineering structures such as ships. Recently, there have been few studies on the application of i4 to shipping; the literature mainly focuses on improving ship operations such as fleet performance monitoring, route optimisation and unmanned ships through big data and IoT [25-27]. There are limited examples of i4 applications in shipbuilding - including the design and construction of ships, which this paper aims to address.

\section{Improvement in Ship Lifecycle Energy Efficiency in Industry 4.0 and Its Key Challenges}

In order to implement i4 technologies in the ship lifecycle to improve overall energy efficiency, the applications of i4 specific to energy consumption and the key challenges faced during each ship lifecycle process are examined and potential solutions are discussed below.

\subsection{Ship Design Process and Potential i4 Applications}

As part of the ship design process, hull form optimisation is an effective method that can help improve the overall energy efficiency of ships [7]. This is achieved by optimising the hull form so that it is more streamlined and reduces overall resistance during the voyage, which will translate to lower fuel and power consumption. As computational intelligence continues to evolve, the role of automated simulation in design and manufacturing of ships will continue to be amplified as a key enabler to help the marine industry to meet new challenges. One potential solution under automated simulation of i4 is the use of a rapid virtual prototyping tool to automate and optimise the ship design process using hull form design and optimisation (HFDO) concept [28]. Here, design improvements and evaluations are carried out automatically in a virtual environment, thereby increasing the possibility of obtaining a more optimum design as compared to the manual improvement process. HFDO integrates the hull modification process using free-form deformation, optimisation through evolutionary algorithm (EA) and performance evaluation using computational fluid dynamics (CFD). A significant advantage of HFDO over traditional methods is that it can help shorten the 
entire design cycle by an appreciable amount to reduce overall ship resistance and power (energy) consumption of the vessel. As demonstrated in [28], the HFDO concept was applied to improve the hull form of an offshore vessel and overall resistance can be reduced up to $12 \%$, which in turn translates to lower fuel and energy consumption. Another significant advantage of automated simulation is that, when coupled with other i4 technologies such as data analytics and cloud computing, it enables the integration of design data such as ship performance and sharing of design tools at different geographical locations. This will potentially help to improve overall design efficiency as well as energy efficiency. The key challenge here is that the actual ship performance data are not made accessible to the shipyard after the vessel is constructed and delivered to the ship owner or operator. Without this feedback loop, it is difficult for a shipyard or ship design firm to monitor performance to improve its future designs.

\subsection{Ship Manufacturing Process and Potential i4 Applications}

During ship manufacturing, large amounts of energy are needed to power the heavy equipment and machinery in the shipyard. It is challenging to monitor the energy consumption of each machine in the entire plant in order to come up with control measures and improve overall energy efficiency. With smart sensors and forecasting tools, energy consumption can be monitored and traced down to the individual machine level. This enables accurate measurement of consumption patterns within the entire shipyard facility and adjustments can be made to improve electrical energy efficiency using a smart energy management system [29]. These smart systems monitor the facility's energy usage at peak and off-peak periods and complement energy usage using a mixture of batteries and renewable energy sources. More recently, automatic and intelligent energy management systems that systematically monitor the drop of facility performance and increase of energy consumption due to ageing and malfunction of equipment have been developed [30]. Automated simulations can be carried out to optimise energy consumption by changing the machine operation schedule or providing an estimation of energy consumption for new facilities. Through IoT and the use of big data analytics, one can also autonomously monitor and control the workshop machinery for health monitoring or change the workflow to allow "real-time" and flexible adjustment in case of machine breakdown or changes in work requirements. The key challenge in ship manufacturing is the poor linkage to the ship design process: design data (digital drawings) are not fed directly into workshop machines and require certain pre-processing to be performed manually before they can be captured and executed by the computer numerical control (CNC) plate cutting or bending machines.

\subsection{Ship Operation Process and Potential i4 Applications}

Ship operation is an important aspect as it consumes the most energy during the entire lifecycle. In the context of i4, ships can be constructed and operated as an intelligent product or smart asset. A product or system can be considered intelligent if it can (i) continuously monitor its status and environment, (ii) react and adapt to environment and operational conditions, (iii) maintain optimal performance in variable circumstances, and (iv) actively communicate with users, the environment and other products and systems [31]. By incorporating enabling i4 technologies such as IoT and big data analytics, ships can also move towards an intelligent product, as described in [32]. As an example, due to constantly changing operating conditions and environment ships are exposed to during each voyage, it is a challenge to effectively monitor all operating parameters, e.g., weather conditions, navigation route, speed, ship draft, and achieve the optimum settings for maximum energy efficiency. The Ship Energy Efficiency Management Plan (SEEMP) was introduced by the IMO to provide guidance for fuel-efficient ship operation. As part of the recommendations, measures such as the use of weather routing to optimise efficiency will help to significantly reduce fuel consumption and, consequently, carbon emissions.

In response to this challenge, i4 can also be extended beyond ship design and manufacturing and applied in ship operations by a combination of IoT, big data analytics and automated simulations. 
While sensors are currently already installed on board vessels to measure key parameters such as vessel speed, loading conditions and environment conditions (wind and current), ship officers are required to manually evaluate the data collected via the sensors and make certain decisions based on personal experience. With i4, this information can now be analysed using big data analytics to automatically plan the optimum route. Equally, such information can be used to modify the ship settings such as adjusting the ballast water or cargo arrangement so that the vessel will consume the minimum fuel. This information can also come from data captured through big data analytics from another fleet of vessels navigating through the same region so as to compare and choose the optimum arrangement or route setting.

Automated simulations can also be carried out before the voyage to forecast the power consumption under various scenarios and hence the optimum route or ship setting can be selected. In another application, by active data collection and condition monitoring, maintenance or repair schedule can be better estimated so that the ship is always running in optimum condition, which leads to lower fuel consumption. For instance, it is well known in the marine industry that barnacles due to bio-fouling accumulated at the bottom of ship hull after prolonged service will increase drag and lead to higher power (fuel) consumption. Through sensors and big data analytics, these barnacles can be detected and analysed to estimate the drag coefficient and predict the optimum schedule for underwater hull cleaning or dry-docking in order to restore a clean hull surface for better energy efficiency. On the developments related to ship engines and emissions, increasingly there is more electric propulsion and clean fuel such as marine gas oil and methanol being used [33]. More intelligent features such as big data analytics and advanced sensors (IoT) are being explored and introduced by major engine manufacturers. As the industry moves towards autonomous vessels, remote monitoring and control of a ship's engine and machinery shore becomes vital. This will be further enhanced by i4-related technologies such as IoT (sensors and communication) and big data analytics for automatic decision-making. Key challenges for implementing these i4 technologies in ship operations include cyber security and integrating different ship systems and equipment into a single operating platform.

\subsection{Examples of it Applications and Their Estimated Energy Savings}

In order to better appreciate how i4 can help to improve the energy efficiency during a ship's lifecycle, we summarise how various i4 technologies can be applied based on examples provided earlier and their estimated energy savings, as illustrated in Table 2.

Table 2. Applications of i4 technologies during the ship lifecycle and estimated energy savings.

\begin{tabular}{cccc}
\hline Parameters & Ship Design & Ship Manufacturing & Ship Operation \\
\hline Applications & $\begin{array}{c}\text { Hull form design } \\
\text { through CAutoD }\end{array}$ & $\begin{array}{c}\text { Factory energy management } \\
\text { and condition monitoring }\end{array}$ & $\begin{array}{c}\text { Weather routing and hull } \\
\text { condition monitor }\end{array}$ \\
\hline $\begin{array}{c}\text { Energy related } \\
\text { aspects }\end{array}$ & $\begin{array}{c}\text { Ship resistance and } \\
\text { power consumption }\end{array}$ & $\begin{array}{c}\text { Equipment usage and power } \\
\text { consumption }\end{array}$ & $\begin{array}{c}\text { Engine power and fuel } \\
\text { consumption }\end{array}$ \\
\hline i4 components & Automated simulations & $\begin{array}{c}\text { Automated simulation, IoT and } \\
\text { big data analytics }\end{array}$ & $\begin{array}{c}\text { Automated simulations, IoT } \\
\text { and big data analytics }\end{array}$ \\
\hline $\begin{array}{c}\text { Estimated energy } \\
\text { savings }\end{array}$ & $\begin{array}{c}\text { Up to 12\% reduction of } \\
\text { fuel consumption [28] }\end{array}$ & $\begin{array}{c}\text { Up to 29\% reduction of factory } \\
\text { power consumption [34] }\end{array}$ & $\begin{array}{c}\text { Up to 10\% reduction of fuel } \\
\text { consumption [35] }\end{array}$ \\
\hline
\end{tabular}

\section{Proposed Closed-Loop Ship Design, Manufacturing and Operation Framework and Future Directions}

In order to address the changing needs of customers and more stringent environmental regulations, shipyards must be able to anticipate trends and modify design or manufacturing processes accordingly. As highlighted in earlier sections, while individual i4 technologies can be applied on their own at each lifecycle stage to reduce power consumption and improve energy efficiency, the maximum benefit can only be achieved by coupling various i4 technologies across the entire product 
lifecycle. To achieve this goal, a framework that aims to integrate various i4 technologies and assemble the aforementioned key challenges into a two-way closed-loop process for a ship lifecycle is proposed in Figure 5.

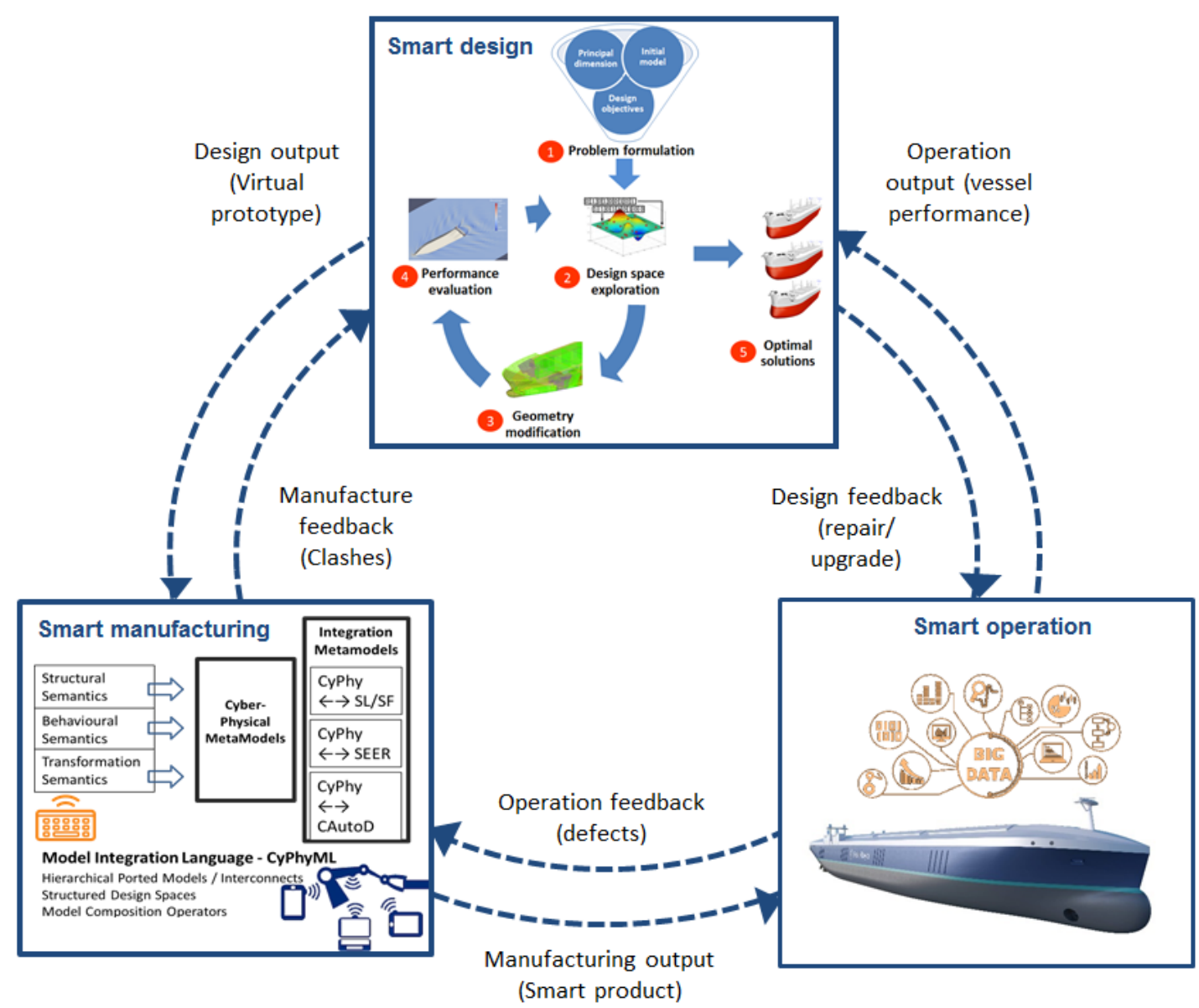

Figure 5. Two-way closed-loop framework for ship design, manufacturing and operation.

\subsection{Closed-Loop Ship Design, Manufacturing and Operation Framework}

Under this proposed framework, smart design is now interconnected with smart manufacturing and smart operations. By connecting the design process to ship operation, an intelligent system based on IoT and big data analytics can be developed to analyse relevant ship operation data captured by onboard sensors and feedback into the design stage to improve energy efficiency for future ship designs. Based on the inputs from smart operation, shipyards can now also predict its customer needs and other possible environmental regulations through business informatics and link up with HFDO to automatically create new hull forms or ship designs which satisfy the latest requirements [36]. Value-added information can also be fed into the design by considering value chain in the constant loop, which may include technical expertise, quality or experiences that are desired by stakeholders or process requirement in the entire ship design and manufacturing workflow [37]. One possible way to capture this expertise and experiences into the design and manufacturing process is through a knowledge-based and intelligent information approach as suggested in [38]. By creating an automatic connection between designs and manufacturing process under this proposed closed-loop framework, any production clashes that occurred during manufacturing can also be feedback directly into the HFDO process to improve the design.

Under smart manufacturing, ship construction can be linked up with both design and operation through i4. With the advancement in the IoT, the gaps between the real and virtual world are closing. 
An example of this is the cyber-physical production system (CPPS), which can be used as an effective platform to connect manufacturing with design. CPPS works as an online network of social machines with mechanical and electronic components, communicated via the network [39]. Smart machines continually share information about stock levels, problems or faults, and changes in orders or demand levels. CPPS not only link machines together, they also create a smart network of machines, properties, information and communications technology (ICT) systems, smart products and individuals across the entire supply chain and full product lifecycle. By connecting ship manufacturing and operation processes, any defects found after the delivery of the vessel can also be monitored and fed back automatically to the manufacturer (shipyard) to improve the manufacturing process.

By closing the loop between ship operation and design through smart operation, useful through-life data such as ship performance, productivity, customer feedback and the latest technologies can be collected, analysed and feedback into an HFDO process for optimum design. These data can be captured through business informatics and big data analytics, which in turn feeds reliable information back to the design process. By filtering away unwanted information and providing proper data analysis, more energy-efficient design can be achieved and the final product can be manufactured in an intelligent and holistic manner.

\subsection{Perceived Milestones and Future Directions}

While i4 may still be in its infancy for industry-wide adoption and much research related to this area is still in progress, its potential is recognised. It is identified as the underlying mechanism needed to integrate existing ship design, manufacturing and operation functions (which are working in silos) in a seamless manner towards a smart product lifecycle. The anticipated milestones and potential impacts from associated i4 technologies for smart design, manufacture and operation are illustrated in Table 3.

Table 3. Milestones and potential impacts for smart design, manufacturing and operation.

\begin{tabular}{|c|c|c|c|c|}
\hline Product lifecycle & Parameters & Near-Term (1-2 Years) & Mid-Term (2-5 Years) & Long-Term (5-10 Years) \\
\hline Smart design & Impact & $\begin{array}{l}\text { Semi-automated hull form } \\
\text { design and optimisation } \\
\text { (HFDO) tool with limited } \\
\text { connection to manufacturing } \\
\text { and operation systems }\end{array}$ & $\begin{array}{l}\text { Highly automated HFDO } \\
\text { with some connection to } \\
\text { manufacturing and } \\
\text { operation systems }\end{array}$ & $\begin{array}{l}\text { Fully automated design with } \\
\text { full connection to } \\
\text { manufacturing and } \\
\text { operation systems and } \\
\text { prediction capabilities based } \\
\text { on market trends and } \\
\text { customer feedback }\end{array}$ \\
\hline \multirow[t]{2}{*}{$\begin{array}{c}\text { Smart } \\
\text { manufacturing }\end{array}$} & Impact & $\begin{array}{c}\text { Limited Cyber-physical } \\
\text { systems (CPS) with } \\
\text { Integrated resource } \\
\text { management for monitoring } \\
\text { and control of project } \\
\text { manpower, cost and } \\
\text { schedule }\end{array}$ & $\begin{array}{c}\text { Partial CPS through } \\
\text { Networked embedded } \\
\text { systems with highly } \\
\text { integrated monitoring and } \\
\text { control system and partial } \\
\text { interface with physical } \\
\text { machinery }\end{array}$ & $\begin{array}{l}\text { Full CPS through centralised } \\
\text { system for monitoring and } \\
\text { control of entire shipyard } \\
\text { processes and interface with } \\
\text { workshop machinery }\end{array}$ \\
\hline & $\begin{array}{l}\text { Enabling i4 } \\
\text { technologies }\end{array}$ & Intelligent robot & $\begin{array}{l}\text { IoT, big data analytics, } \\
\text { intelligent robot }\end{array}$ & $\begin{array}{l}\text { Automated simulations, IoT, } \\
\text { big data analytics, intelligent } \\
\text { robot, additive } \\
\text { manufacturing }\end{array}$ \\
\hline Smart operation & Impact & $\begin{array}{l}\text { Semi-automated ship } \\
\text { operation with onboard } \\
\text { monitoring of ship } \\
\text { performance data for vessel } \\
\text { planning and maintenance } \\
\text { schedule }\end{array}$ & $\begin{array}{l}\text { Highly automated ship } \\
\text { operation with minimal } \\
\text { onboard crews and some } \\
\text { remote monitoring of ship } \\
\text { performance data and } \\
\text { voyage planning from } \\
\text { onshore }\end{array}$ & $\begin{array}{l}\text { Fully autonomous and } \\
\text { unmanned ship operation } \\
\text { through remote monitoring } \\
\text { and planning from onshore }\end{array}$ \\
\hline
\end{tabular}


By adopting the concepts of the smart product lifecycle through i4, it is possible to transform the way future ships are designed, manufactured and operated. i4 can be used to intelligently search and mine for hidden data characteristics or trends that may be geographically distributed to create new and innovative ship designs. Big data analytics can be used to link up information across the product lifecycle such as fuel consumption and travel patterns collected during ship operation and incorporate this into early design stage for similar vessels. Using machine learning and automated simulation, this information can be used to produce optimum ship design, which is more fuel-efficient. Through a closed-loop process for ship design, manufacturing and operation, the entire ship design and construction process can now be closely monitored and workshop machines seamlessly connected through CPS. With centralised information collection and control, production efficiency will be increased and wastages due to error reduced. This will help to reduce the overall workshop power consumption to output ratio, therefore improving overall energy efficiency. Ships can become highly or fully automated as they move toward minimal or unmanned operation through automated simulations, IoT and big data analytics. Highly automated or unmanned vessels apply 'real-time' analysis of the environmental and vessel conditions to ensure the optimum route or even adjust the loading conditions of the vessel accordingly in order to improve the overall power (energy) efficiency. As i4 continues to develop, it is recognised that cyber security and system integration need to be improved in order to allow adoption of these i4 technologies by mainstream ship operation, design and manufacturing processes.

\section{Conclusions}

Industry 4.0 is rapidly gaining momentum worldwide and is set to change the way products are manufactured. Unlike consumer products, engineering structures such as ships have a different set of design, manufacturing and operation requirements that need to be addressed independently in the i4 environment. Ship design, manufacturing and operation are highly complex process and consume high amounts of energy throughout the entire lifecycle. To survive in this competitive market, shipyards need to design and build ships that are more energy-efficient and innovative. Through computer intelligence and cyber-physical integration, we envision that i4 can revolutionise ship design, manufacturing and operation as a smart product through-life. By providing some insights into the ship lifecycle and potential i4 applications as well as the proposed two-way closed-loop framework, we hope we can encourage the adoption of i4 technologies and through-life concepts so as to improve the overall energy efficiency of the design, manufacturing and operation of ships in the near future.

Acknowledgments: This research was funded by Economic Development Board (EDB) of Singapore and Sembcorp Marine Ltd. (SCM) under the Industrial Postgraduate Programme (IPP) Grant No. COY-15-IPP/140002, and by the Engineering and Physical Sciences Research Council (EPSRC) of the UK under Grant EP/P001246.

Author Contributions: Joo Hock Ang proposed the i4 timeline and two-way closed-loop framework for ship design, manufacturing and operation; Yun Li and Cindy Goh provided the CAutoD and industry 4.0 concepts and supervision of this project; Alfredo Alan Flores Saldivar contributed to the cyber-physical metamodels and business informatics; Joo Hock Ang wrote the paper.

Conflicts of Interest: The founding sponsors had no role in the design of the study; in the collection, analyses, or interpretation of data; in the writing of the manuscript, and in the decision to publish the results. Yun Li is the guest editor of the Energies Special Issue, "Smart Design, Smart Manufacturing and Industry 4.0", but is not involved in any reviewing processes of this paper.

\section{References}

1. International Maritime Organization. Available online: http://www.imo.org/OurWork/ TechnicalCooperation/ITCP/Pages/Default.aspx (accessed on 15 November 2015).

2. Energy Efficiency Made in Germany. Available online: http://www.efficiency-from-germany.info/ ENEFF/Navigation/EN/Energyefficiency/Transport/InlandWaterways/inland-waterways.html (accessed on 15 November 2015). 
3. U.S. Energy Information Administration (EIA). International Energy Outlook 2016; U.S. EIA: Washington, DC, USA, 2016.

4. Hughes, D. Shipping Commits to $\mathrm{CO}_{2}$ Roadmap; The Business Times: Singapore, 2016.

5. Ang, J.H.; Goh, C.; Li, Y. Key challenges and opportunities in hull form design optimisation for marine and offshore applications. In Proceedings of the 21st International Conference on Automation \& Computing, Glasgow, UK, 11-12 September 2015.

6. ABB. Available online: http://www.abb.com/cawp/seitp202/14e177677aa71662c12579ff003fad9d.aspx (accessed on 6 March 2017).

7. Shipping 2020. In DNV Report: Executive Summary; Det Norske Veritas AS: Høvik, Norway, 2012.

8. Montalvo, C.; Peck, D.; Rietveld, E. A Longer Lifetime for Products: Benefits for Consumers and Companies; Study for Internal Market and Consumer Protection (IMCO) Committee; European Parliament: Brussels, Belgium, 2016.

9. Lee, J.; Lapira, E.; Bagheri, B.; Kao, H.A. Recent advances and trends in predictive manufacturing systems in big data environment. Manuf. Lett. 2013, 1, 38-41. [CrossRef]

10. Kagermann, H.; Wahlster, W.; Helbig, J. Recommendations for Implementing the Strategic Initiative INDUSTRIE 4.0; Acatech National Academy of Science and Engineering: Frankfurt, Germany, 2013.

11. Mario, H.; Tobias, P.; Boris, O. Design Principles for Industrie 4.0 Scenarios: A Literature Review; Working Paper, No. 01-2015; Technical University of Dortmund: Dortmund, Germany, 2015.

12. Posada, J.; Toro, C.; Barandiaran, I.; Oyarzun, D.; Stricker, D.; Amicis, R.; Pinto, E.; Eisert, P.; Dollner, J.; Vallarino, I. Visual computing as a key enabling technology for industrie 4.0 and industrial internet. IEEE Comput. Gr. Appl. 2015, 35, 26-40. [CrossRef] [PubMed]

13. International Electrotechnical Commission (IEC). Factory of the Future-White Paper; IEC: Geneva, Switzerland, 2015.

14. ZDNet. Available online: http://www.zdnet.com/article/germanys-vision-for-industrie-4-0-therevolution-will-be-digitised/ (accessed on 6 December 2016).

15. Siemens. Available online: http://www.siemens.co.uk/en/news_press/index/news_archive/2014/uksfirst-digital-factory-demonstrator-launched.htm (accessed on 6 November 2016).

16. Basque Business Development Agency. Available online: http://www.spri.eus/en/basque-industry-4-0 (accessed on 1 March 2017).

17. PR Newswire. Available online: http://www.prnewswire.com/news-releases/smart-manufacturingleadership-coalition-will-lead-the-new-smart-manufacturing-innovation-institute-300287952.html (accessed on 6 December 2016).

18. PTC. Available online: http://www.ptc.com/product-lifecycle-report/china-asia-carve-out-stake-inindustry-4-0 (accessed on 8 November 2016).

19. Kasetsart Energy and Technology Management Center. Available online: http://www.wise.co.th/wise/ Knowledge_Bank/References/Everything_4/Revolution_to_Industry_4.pdf (accessed on 8 November 2016).

20. CIO Asia. Available online: http://www.cio-asia.com/resource/emerging-technology/singapore-willcontinue-investing-in-advanced-manufacturing-iswaran/ (accessed on 12 November 2016).

21. Lee, J.; Kao, H.A.; Yang, S.H. Cyber-physical systems: service innovation and smart analytics for industry 4.0 and big data environment. Procedia CIRP 2014, 16, 3-8. [CrossRef]

22. Rubmann, M.; Lorenz, M.; Gerbert, P.; Waldner, M.; Justus, J.; Engel, P.; Harnisch, M. Industry 4.0; Boston Consulting Group: Boston, MA, USA, 2015.

23. Nazir, M. Cloud computing: Overview \& current research challenges. J. Comput. Eng. 2012, 8, 14-22.

24. Deloitte Report on Industry 4.0-Challenges and Solutions for Digital Transformation and Use of Exponential technologies; Deloitte: Zurich, Switzerland, 2015.

25. Hribernik, K. Industry 4.0 in the Maritime Sector. In Sea Japan; 13 April 2016. Available online: http: //www.mlit.go.jp/common/001127983.pdf (accessed on 12 April 2017).

26. Etienne, M.; Sayers, A. The internet of things for smarter, safer, connected ships. In Proceedings of the 15th International Conference on Computer and IT Applications in the Maritime Industries (COMPIT '16), Lecce, Italy, 9-11 May 2016.

27. Rødseth, O.J.; Perera, L.P.; Mo, B. Big data in shipping-Challenges and opportunities. In Proceedings of the 15th International Conference on Computer and IT Applications in the Maritime Industries (COMPIT '16), Lecce, Italy, 9-11 May 2016. 
28. Ang, J.H.; Goh, C.; Li, Y. Hull form design optimisation for improved efficiency and hydrodynamic performance of 'ship-shaped' offshore vessels. In Proceedings of the International Conference on Computer Applications in Shipbuilding, Bremen, Germany, 29 September-1 October 2015.

29. Feng, X.; Gooi, H.B.; Chen, S.X. Capacity fade-based energy management for lithium-ion batteries used in PV systems. Electr. Power Syst. Res. 2015, 129, 150-159. [CrossRef]

30. Lee, H.J.; Yoo, S.K.; Kim, Y.W. An energy management framework for smart factory based on context-awareness. In Proceedings of the 18th International Conference on Advanced Communication Technology (ICACT), 31 January-3 February 2016.

31. Venta, O. Intelligent Products and Systems; Technical Report; VTT Technical Research Centre of Finland: Espoo, Finland, 2007.

32. Meyer, G.G.; Främling, K.; Holmströmc, J. Intelligent products: A survey. Comput. Ind. 2009, 60, 137-148. [CrossRef]

33. Rolls-Royce. Available online: https://www.rolls-royce.com/products-and-services/marine/shipintelligence/discover/smart-shipping.aspx\#section-overview (accessed on 8 March 2017).

34. Lee, D.; Cheng, C.C. Energy savings by energy management systems: A review. Renew. Sustain. Energy Rev. 2016, 56, 760-777. [CrossRef]

35. Sharifi, Y.; Ghassemi, H.; Zanganeh, H. Various innovative technologic devices in shipping energy saving and diminish fuel consumption. Int. J. Phys. 2017, 5, 21-29.

36. Ang, J.H.; Goh, C.; Li, Y. Smart Design for Ships in a Smart Product Through-Life and Industry 4.0 Environment. In Proceedings of the IEEE World Congress on Computational Intelligence (IEEE WCCI '16), Vancouver, BC, Canada, 24-29 July 2016; pp. 5301-5308.

37. Andrew, F.; Shunk, D.D.; Callarman, T.D. Value Chains versus Supply Chains. Available online: http:/ / www.bptrends.com/bpt/wp-content/publicationfiles/03\%2D06\%2DART\%2DValueChains\% 2DSupplyChains\%2DFeller\%2Epdf (accessed on 29 April 2017).

38. Saldivar, A.A.; Li, Y.; Chen, W.N.; Zhan, Z.H.; Zhang, J.; Chen, L.Y. Industry 4.0 with cyber-physical integration: A design and manufacture perspective. In Proceedings of the 21st International Conference on Automation \& Computing, Glasgow, UK, 11-12 September 2015.

39. Toroa, C.; Barandiarana, I.; Jorge Posadaa, J. A perspective on knowledge based and intelligent systems implementation in industrie 4.0. Procedia Comput. Sci. 2015, 60, 362-370. [CrossRef] 